\title{
A PAISAGEM DA FLORESTA URBANA DE CURITIBA-PR
}

\author{
URBAN FOREST LANDSCAPE OF CURITIBA-PR
}

\author{
Mayssa Mascarenhas Grise ${ }^{1}$, Daniela Biondi², Hideo Araki ${ }^{3}$
}

\section{RESUMO}

A vegetação é o componente central da estrutura das paisagens urbanas, seja por seus benefícios ecológicos, estéticos ou sociais. O objetivo desse trabalho foi descrever e quantificar a composição e configuração espacial dos componentes estruturais da paisagem da floresta urbana de Curitiba-PR. Para identificar a floresta urbana utilizou-se imagens GeoEye-1, às quais foram aplicadas técnicas de realce para a classificação por árvore de decisão. Após a classificação foram definidos os componentes estruturais da paisagem, a matriz, os fragmentos e os corredores. A paisagem de Curitiba é formada por uma matriz urbana que ocupa $56,33 \%$ da área total do município. Os fragmentos, classificados como as áreas com cobertura de vegetação presentes nas áreas verdes e no interior das áreas de quadra, ocupam $37,90 \%$. Os corredores, definidos como a vegetação presente sobre o arruamento e os corpos d'água, representam $5,73 \%$. Ainda que Curitiba detenha uma matriz formada por áreas construídas imersa em uma extensa ( $44 \%$ da paisagem) floresta urbana, há necessidade de um incremento no número de fragmentos remanescentes, de uma efetiva fiscalização que evite a perda dos fragmentos introduzidos particulares e, de um monitoramento e manejo adequado dos corredores do tipo urban stepping stones.

Palavras-chave: Arborização; Área verde; Matriz; Corredor; Fragmento.

\section{ABSTRACT}

Vegetation is the central component of the urban landscape structure, whether by their ecological, aesthetic or social benefits. The aim of this study was to describe and quantify the composition and spatial configuration of landscape structural components of Curitiba-PR urban forest. The urban forest was identified by GeoEye-1 images, which were applied enhancement techniques for classification by decision tree. After classification, the landscape structural components were defined: the matrix, patches and corridors. Curitiba's landscape is formed by an urban matrix that occupies $56.33 \%$ of city total area. The patches, classified as vegetation covered in green areas and block areas inside, occupies $37.90 \%$. Corridors, defined as the vegetation covered on streets and water bodies, represent $5.73 \%$. Although Curitiba holds a matrix of built areas immersed in an extensive (44\% of the landscape) urban forest, there is a need to increase the number of remaining patches, an efficient supervision to prevent the loss of private introduced patches and a monitoring and appropriate management of the urban stepping stones corridors.

Keywords: Tree; Green area; Matrix; Corridor; Patch.

Recebido em 17.06.2016 e aceito em 14.07.2016

1 Bióloga, Dra., Programa de Pós-graduação em Engenharia Florestal da Universidade Federal do Paraná. Curitiba/PR. Email: mayssamonteiro@gmail.com

2 Engenheira Florestal, Dra., Professora do Departamento de Ciências Florestais da Universidade Federal do Paraná. Curitiba/PR Email: dbiondi@ufpr.br

3 Engenheiro Cartógrafo, Dr., Professor do Departamento de Geomática da Universidade Federal do Paraná. Curitiba/PR. Email: haraki@ufpr.br 


\section{INTRODUÇÃO}

As paisagens urbanas são o produto das ações do homem sobre a natureza (BIONDI, 2015). A vegetação é um componente central da estrutura dessa paisagem, seja por motivos ecológico, climático e também sociopsicológico (LANG; BLASCHKE, 2009).

Uma paisagem é formada por três componentes estruturantes: a matriz, os fragmentos e os corredores. A matriz da paisagem é definida como a classe de cobertura do solo que ocupa a maior área de cobertura da paisagem, com maior grau de conectividade e que controla a dinâmica da paisagem (FORMAN; GODRON, 1986; LANG; BLASCHKE, 2009).

Os fragmentos são elementos individuais cujo uso do solo difere do da matriz. Estão inseridos em uma matriz cujas características diferem em espécies, estrutura ou composição. Segundo Forman e Godron (1986), os fragmentos podem ser categorizados por sua origem ou mecanismo de sua causa.

Os corredores são áreas lineares que comunicam um lugar a outro. Esta é a definição clássica de Forman e Godron (1986), os quais classificam os corredores em três tipos: lineares, em faixas e de corpos d'água. Entretanto, Lang e Blaschke (2009) destacam que ainda não há uma definição clara e consistente para o termo corredor. Os autores enfatizam que a maioria das definições tem uma componente espacial-estrutural (alongada) e outra componente funcional (caráter conectivo, via para movimentação de organismos). Em 1995, a Estratégia Pan-europeia para a Diversidade Biológica e Paisagística - PEBLDS, diante da dificuldade de se estabelecer corredores lineares e contínuos em paisagens extremamente fragmentadas e engessadas pela sua constituição histórica de povoamento, apoiou e incentivou a inclusão e constituição de corredores de paisagem não somente condicionados à forma alongada e à junção física, mas acedeu à ideia de corredores de trampolins ecológicos, ou stepping stones. Assim, fortalece-se a noção de que o termo conectividade deve ser entendido na acepção de união funcional, diferente de junção, que é a união física (LANG; BLASCHKE, 2009).

Diversos autores defendem a formação de um sistema de áreas verdes nas cidades como forma de otimizar a funcionalidade da floresta urbana (FORMAN; GODRON, 1986). Estudos têm apontado para a efetividade destes na dispersão de espécies vegetais e animais em áreas urbanas, como Woodall et al. (2010) e Vergnes, Viol e Clergeau (2012). Um desenho ideal das áreas verdes exige um sistema de vegetação incorporado à malha urbana. Isto segrega as áreas construídas, aumenta o impacto paisagístico e facilita as funções ambientais e ecológicas (FORMAN; GODRON, 1986).

Diante da necessidade de se reestruturar os ambientes urbanos, o que não é possível sem considerar a vegetação (a qual atua diretamente na qualidade do solo, da água e do ar), cada vez mais vem se discutindo o planejamento e o desenvolvimento das paisagens urbanas 
no âmbito da ecologia. Entretanto, antes de se iniciar estudos em ecologia urbana, é essencial a coleta de informações básicas que possam dar suporte a tais pesquisas. Desta forma, a quantificação, a qualificação e a espacialização da vegetação urbana são fundamentais nestes processos.

A distribuição da vegetação urbana influi diretamente em suas funções ecológica, estética e social. Portanto, um planejamento urbano baseado nos padrões espaciais de configuração da paisagem pode resultar em uma convivência equilibrada dos habitantes com os componentes urbanos.

Ferramentas geoespaciais como o Sensoriamento Remoto (SR) e os Sistemas de Informação Geográfica (SIGs) podem fornecer dados espaciais, a partir dos quais a vegetação urbana pode ser identificada, quantificada, qualificada e analisada quanto à sua distribuição espacial na cidade. Neste sentido, a utilização de dados do SR de alta resolução espacial na identificação da vegetação, bem como o posterior processamento dos dados em SIGs, permitem a análise detalhada da composição e configuração da paisagem urbana através de seus componentes estruturais, matriz, fragmentos e corredores, os quais, auxiliados pelo cálculo de métricas, permite possibilitam a elaboração de um diagnóstico da paisagem urbana. A partir de um diagnóstico apropriado, tem-se o entendimento das implicações específicas resultantes dessa configuração para a integridade, utilidade e valor da paisagem (LANG; BLASCHKE, 2009).

O objetivo do presente trabalho foi descrever e quantificar a composição e configuração espacial dos componentes estruturais - matriz, fragmentos e corredores - da paisagem da floresta urbana de Curitiba-PR por meio de técnicas do sensoriamento remoto de alta resolução espacial, com a finalidade de gerar informações espaciais que sirvam de base para o planejamento de uso e ocupação do solo urbano.

\section{MATERIAL E MÉTODOS}

\section{Área de Estudo}

A área de estudo foi o município de Curitiba, capital do estado do Paraná, na região sul do Brasil. O marco zero da cidade, localizado na Praça Tiradentes, tem as coordenadas $25^{\circ}$ $25^{\prime} 41^{\prime \prime}$ de latitude $S$ e $25^{\circ} 25^{\prime} 41^{\prime \prime}$ longitude W. A cidade foi fundada em 1693 e atualmente é dividida em 75 bairros dispostos em nove unidades administrativas ou regionais: Bairro Novo, Boa Vista, Boqueirão, Cajuru, Cidade Industrial de Curitiba (CIC), Matriz, Portão, Pinheirinho e Santa Felicidade (IPPUC, 2014). 
Localizada no primeiro planalto paranaense, Curitiba ocupa uma área de 432,17 km² com altitude média em relação ao nível do mar de 934,6 m. A topografia é ondulada com colinas suavemente arredondadas. A geologia é composta por sedimentos de formação Guabirotuba de origem flúvio-lacustre. Segundo a classificação de Köppen, o clima é do tipo Cfb, subtropical (ou temperado) úmido, mesotérmico, sem estação seca, com verões frescos e invernos com geadas frequentes (IPPUC, 2014).

A cidade está inserida na região fitogeográfica de limite de Campo (Estepe GramíneoLenhosa) com Mata de Araucária (Floresta Ombrófila Mista) que compõe o Bioma Mata Atlântica. Possui mais de mil áreas verdes além de 300 mil árvores de rua (IPPUC, 2014). A cobertura vegetal de todo o município, em 2004, foi estimada por Vieira e Biondi (2008) em $129.940 .000 \mathrm{~m}^{2}$ ou $30 \%$ do seu território.

Reconhecida internacionalmente como capital ecológica, Curitiba tem seu desenvolvimento histórico relacionado às questões ambientais desde 1721, quando chega à cidade o ouvidor Raphael Pires Pardinho, a primeira autoridade a se preocupar com os aspectos ambientais da cidade. No século XIX iniciou-se a "arborização" de Curitiba com o plantio das primeiras árvores em ruas e praças. A década de 1870 marcou o início do processo de arborização dos largos (precursores das praças) da capital, com a criação do "Cinturão Verde" no entorno da cidade e o plantio das primeiras árvores em ruas, praças e parques. $O$ Passeio Público foi o primeiro parque da cidade, inaugurado em 1886. Somente em 1966 foi estabelecido o Plano Diretor, o qual conduziu o crescimento da cidade associado à conservação das áreas verdes e à qualidade de vida dos cidadãos (IPPUC, 2014).

\section{Identificação da floresta urbana por meio de imagens digitais}

Para a realização desta pesquisa foram utilizadas imagens do satélite GeoEye-1, com as bandas do visível e infravermelho próximo, que contemplaram a totalidade do município. As imagens fusionadas apresentam uma resolução espacial de $0,5 \mathrm{~m}$ e dataram de janeiro de 2010, ou seja, foram adquiridas na melhor estação do ano para tal finalidade, o verão. Para a classificação das imagens digitais foi utilizado o método da Árvore de Decisão, sendo estabelecido um conjunto de regras de decisão, baseado no comportamento da vegetação quando realçada pelas técnicas do NDVI (Normalized Difference Vegetation Index) e nas transformações por Componentes Principais (CP) e no espaço de cores - matiz, saturação e valor (Hue, Saturation, Value - HSV). A Árvore de Decisão permitiu criar as regras de decisão, as quais foram implementadas no ambiente MATLAB.

O pós-processamento foi realizado em ambiente computacional SIG no software ArcGIS 10. Os arquivos contendo as informações da cobertura de vegetação de Curitiba foram 
transformados do formato matricial (raster) para vetorial. Com as informações vetorizadas obteve-se acesso aos dados da tabela de atributos, na qual foi calculada a área dos polígonos de vegetação.

Uma vez definida a cobertura de vegetação da cidade e de suas regionais, os componentes da floresta urbana foram divididos em floresta urbana em área pública e floresta urbana em área particular, conforme Biondi (2015).

Foi considerada floresta urbana particular, toda a cobertura de vegetação em área particular (BIONDI, 2015), ou seja, os quintais e jardins - áreas cobertas por vegetação localizadas dentro dos limites das quadras e lotes, segundo os dados vetoriais de arruamento da cidade, fornecidos pelo IPPUC.

Foi considerada floresta urbana pública toda a cobertura de vegetação sobre as áreas verdes públicas e a arborização viária (BIONDI, 2015). As áreas verdes foram identificadas a partir do arquivo vetorial fornecido e elaborado pelo IPPUC, e a arborização viária foi definida como sendo toda a cobertura de vegetação encontrada sobre o arruamento - ruas, avenidas, calçadas e demais acessos da cidade (BIONDI, 2015). Foram cruzados, no software ArcGIS, o arquivo vetorial da cobertura de vegetação com os arquivos vetoriais de áreas verdes e do arruamento a fim de se obter a floresta urbana pública de Curitiba.

\section{Componentes estruturais da paisagem}

A paisagem da floresta urbana de Curitiba-PR foi caracterizada por meio da análise dos componentes estruturais da paisagem - a matriz, os fragmentos e os corredores. Esta definição foi baseada em Forman e Godron (1986), os precursores do estudo da paisagem no século $X X$.

A matriz da paisagem da floresta urbana de Curitiba e de suas regionais foi definida pelos seguintes critérios (FORMAN; GODRON, 1986):

a) área relativa - a classe de cobertura do solo de maior representatividade e extensão ao longo da paisagem;

b) conectividade e controle da dinâmica da paisagem - a classe de cobertura do solo de maior conectividade e que detém o controle sobre a dinâmica da paisagem.

Para esta pesquisa foram considerados somente os corredores formados por vegetação, os quais foram baseados nos tipos propostos por Forman e Godron (1986) e Lang e Blaschke (2009), tais como:

a) corredores lineares de vegetação - caracterizados por estreitas faixas de vegetação dominadas por espécies de borda de fragmentos, aqui considerada a cobertura de vegetação sobre o arruamento que formaram faixas com área superior a $7.500 \mathrm{~m}^{2}$; 
b) corredores em quadra - corresponde à vegetação sobre o arruamento com área de cobertura de 500 a $7.500 \mathrm{~m}^{2}$;

c) corredores urban stepping stones ou trampolins ecológicos urbanos - foram caracterizados pela cobertura de vegetação sobre o arruamento com área inferior a $500 \mathrm{~m}^{2}$;

d) corredores em faixas de vegetação - caracterizados por largas faixas de vegetação que possuem uma área central contendo espécies de interior, aqui definidos como sendo a cobertura de vegetação sobre o arruamento com área superior a $7.500 \mathrm{~m}^{2}$ e que se apresentaram de forma arredondada ou triangular;

e) corredores de corpos d'água - foi considerada a cobertura de vegetação sobre os corpos d'água e que consequentemente acompanham a margem de rios e arroios ou lagos e cavas.

Os parâmetros utilizados no estabelecimento das áreas de cada tipo de corredor foram:

a) área de $500 \mathrm{~m}^{2}$ - corresponde à maior área de copa encontrada na arborização de Curitiba em estudo realizado por Bobrowski e Biondi (2012) por meio de inventário florestal;

b) área de $7.500 \mathrm{~m}^{2}$ - corresponde à área padrão de arruamento ao longo de uma quadra, baseado na Lei n. 2.942/1966 (CURITIBA, 1966). Esta Lei regulamenta os projetos de arruamento e loteamento de Curitiba e estabelece que as vias públicas não devem exceder $300 \mathrm{~m}$ e as secções transversais terão de 12 a $25 \mathrm{~m}$, sendo $25 \mathrm{~m}$ o valor mínimo para vias expressas (CURITIBA, 1966). Assim calculou-se a área padrão de arruamento (300 m x 25 m) igual a $7.500 \mathrm{~m}^{2}$.

Estas categorias de corredores foram estabelecidas para que fosse possível realizar uma análise minuciosa da distribuição da arborização viária da cidade, de forma a considerar toda a vegetação componente da arborização viária como formadora de corredores. Incluem-se assim as pequenas áreas de vegetação (até $500 \mathrm{~m}^{2}$ ), como os trampolins ecológicos urbanos, a vegetação presente ao longo da área de uma quadra (de 500 a $7.500 \mathrm{~m}^{2}$ ), e os grandes corredores (área superior a $7.500 \mathrm{~m}^{2}$ ). Estes três tipos somados aos corredores de corpos d'água e corredores em faixa permitiram o estudo da paisagem com maior detalhamento, de forma a aprimorar a análise do sistema formado pela floresta urbana de Curitiba.

Com base nos tipos de fragmentos propostos por Forman e Godron (1986), foi feita uma adaptação e os fragmentos foram definidos como:

a) fragmentos remanescentes - são ilhas de vegetação que resistiram a um distúrbio generalizado nas áreas ao seu redor, mas que preservam características intrínsecas da biota nativa. Neste estudo foram considerados os parques (de conservação, lineares e de lazer), bosques (nativos relevantes, de conservação e de lazer), RPPNM e áreas verdes diversas (aquelas que constam no arquivo base do IPPUC, mas cuja tipologia não é definida) com área maior que $100.000 \mathrm{~m}^{2}$. Este valor foi estipulado, considerando que $99,76 \%$ das praças de 
Curitiba apresentam área inferior a $100.000 \mathrm{~m}^{2}$ e $41,66 \%$ dos parques e bosques apresentam área superior a este valor;

b) fragmentos de perturbação - são originários de áreas de vegetação que sofreram um distúrbio produzido pela matriz, sendo muitas vezes descaracterizados, mas que ainda apresentam certa cobertura de vegetação. Sendo assim, foram considerados as praças, os eixos de animação e as áreas verdes diversas com área de 2.500 a $100.000 \mathrm{~m}^{2}$. Este é o intervalo entre a área mínima de uma praça, conforme estabelece o Decreto n. 427 de 1983 (CURITIBA, 1983), e a área definida para os fragmentos remanescentes;

c) fragmentos introduzidos públicos - são áreas com vegetação plantada, independente do porte. Foi considerada a vegetação inserida pela municipalidade em área verde pública, tais como: jardinetes, largos, jardins ambientais, núcleos ambientais, centro poliesportivo e as áreas verdes diversas menores que $2.500 \mathrm{~m}^{2}$;

d) fragmentos introduzidos particulares - são áreas com vegetação plantada e/ou manejada diretamente pelos habitantes de determinado local. Foi considerada somente a cobertura de vegetação dentro dos limites das quadras, segundo os dados vetoriais de arruamento da cidade.

\section{RESULTADOS E DISCUSSÃO}

\section{Análise da estrutura da paisagem da floresta urbana de Curitiba-PR}

Baseado nos dados vetoriais do IPPUC de 2010, Curitiba possui uma área total de 434.530.889,27 $\mathrm{m}^{2}$. A classificação das imagens digitais resultou em uma área total de cobertura de vegetação de 189.826.140,18 $\mathrm{m}^{2}$.

Para a análise da estrutura da paisagem da floresta urbana de Curitiba-PR, foram considerados somente os polígonos de vegetação com área maior que $0,25 \mathrm{~m}^{2}$ ou um píxel. Desta forma, $0,03 \%$ da área total de Curitiba classificado como vegetação foram desconsiderados para o estudo da paisagem. Foram 911.989 polígonos que, quando somados, não apresentaram tamanho significativo de área que viesse a interferir na análise da paisagem. Mas que, devido ao elevado número de pequenos polígonos, inviabilizaria o processamento das métricas de paisagem.

A estrutura da paisagem de Curitiba apresentou como matriz sua área sem cobertura de vegetação. Os fragmentos foram formados pelas áreas com cobertura de vegetação. Os corredores foram compostos pelas áreas com cobertura de vegetação que conectam os fragmentos (Figuras 1 e 2). 
A matriz da paisagem foi definida pelo método da área relativa como sendo a área sem cobertura de vegetação, a qual representou $224.763 .417,39 \mathrm{~m}^{2}$ ou $56,33 \%$ da área total do município (Figuras 1 e 2). A matriz, portanto, é formada por áreas impermeáveis construídas, tais como: casas comerciais, indústrias, residências, sistema viário e as estruturas e equipamentos das empresas de energia elétrica, de água e saneamentos e de telecomunicações; e ainda por áreas permeáveis como solo exposto e corpos d'água. Segundo Biondi (2015), na paisagem urbana a matriz detém o controle dos fragmentos e corredores.

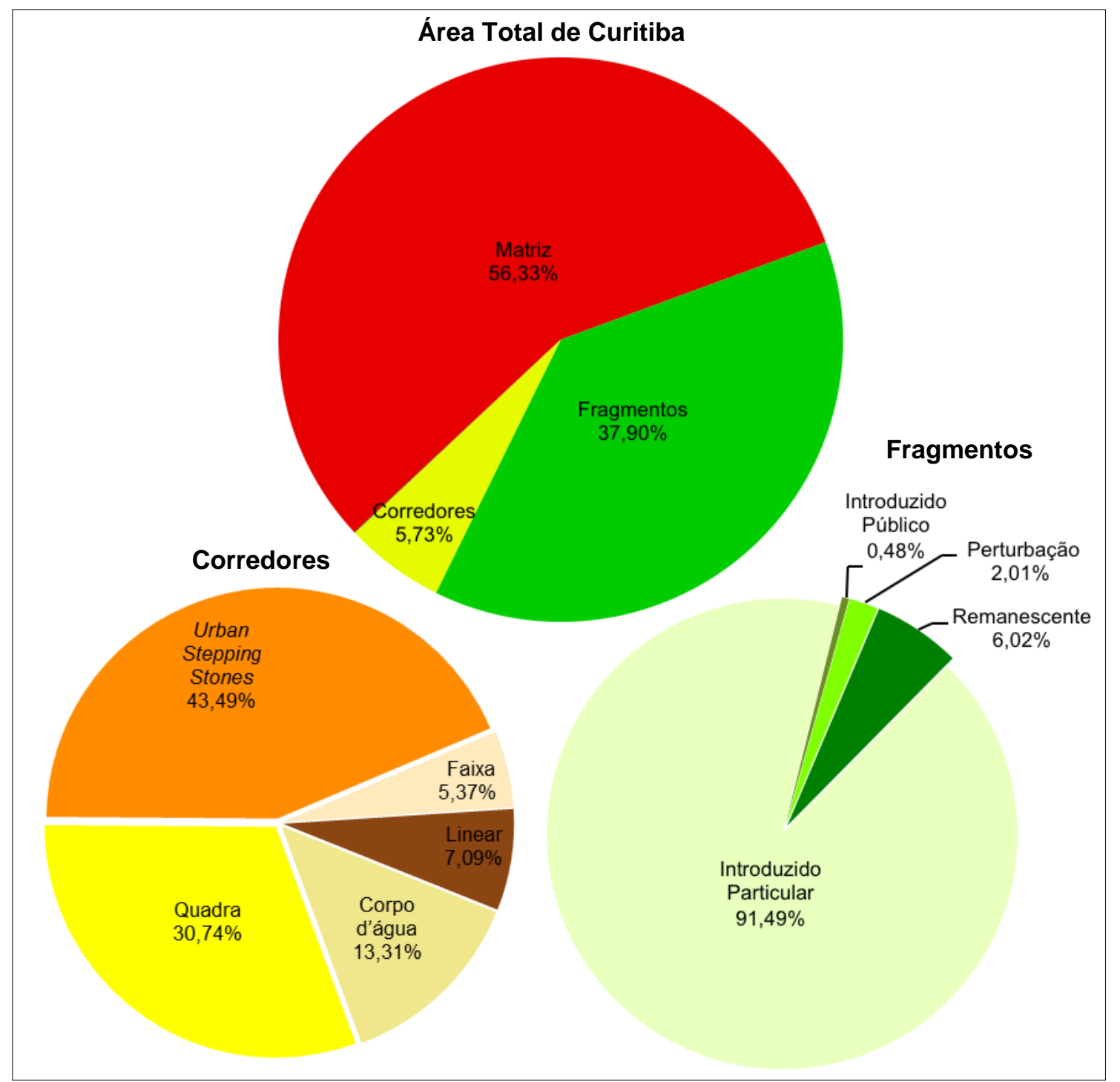

Figura 1. Estrutura da paisagem da floresta urbana de Curitiba-PR

Figure 1. Urban forest landscape structure of Curitiba-PR 


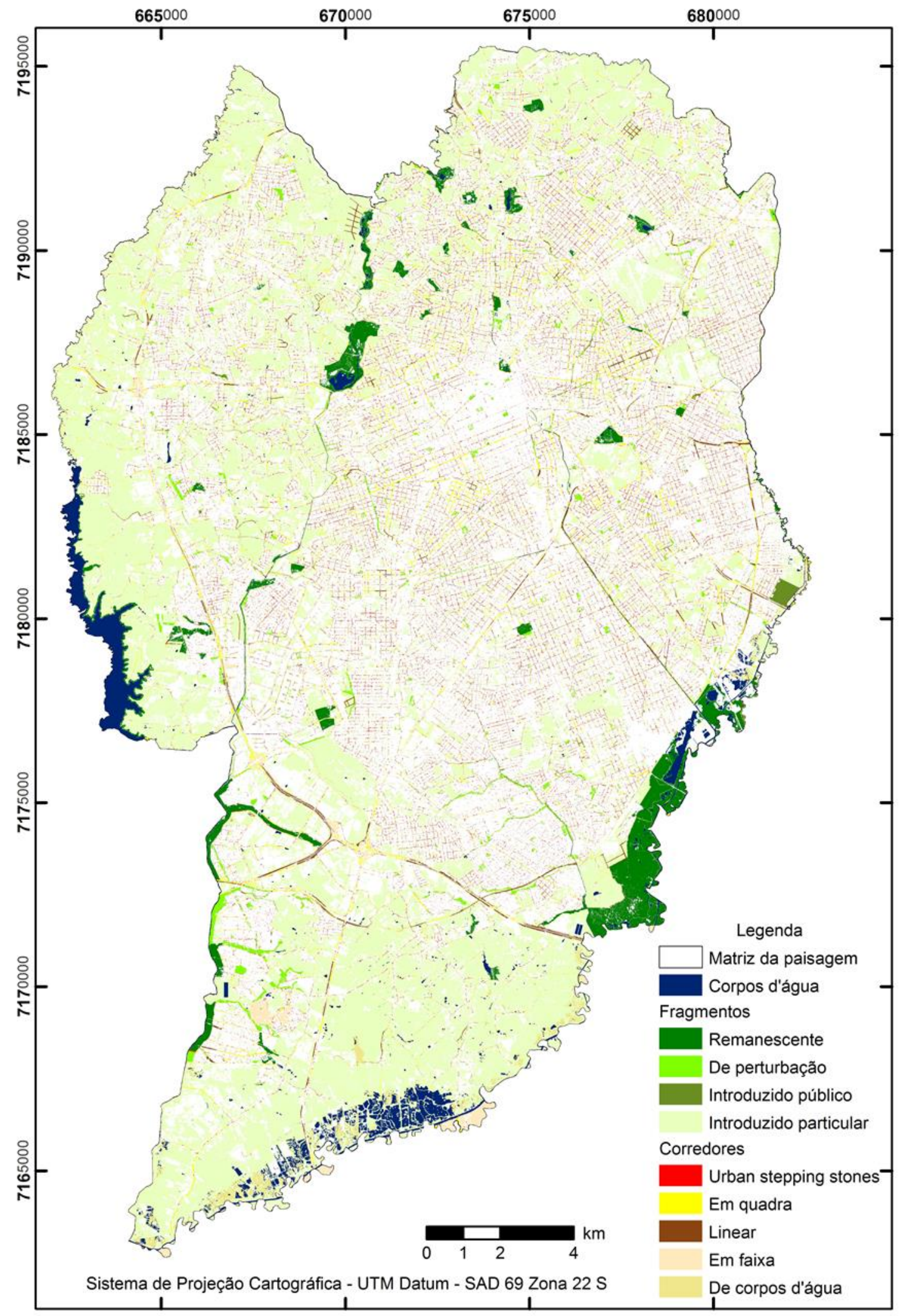

Figura 2. Estrutura da paisagem da floresta urbana de Curitiba-PR

Figure 2. Urban forest landscape structure of Curitiba-PR 
Parece óbvio que a matriz de uma cidade seja, em grande parte, formada por área construída. Entretanto, comprovar que a matriz da paisagem de Curitiba corresponde à apenas $56 \%$ da área da cidade é surpreendentemente positivo, uma vez que os outros $44 \%$ (ou quase a metade) da cidade são cobertos por vegetação. $O$ objeto de estudo desta pesquisa foi a cobertura de vegetação (independente do porte) presente (em cada 0,25 $\mathrm{m}^{2}$ de área) na cidade. Todo e qualquer outro elemento na paisagem (incluindo os corpos d'água sem cobertura de vegetação) foi considerado como componente da matriz. A matriz desempenha um papel relevante para o fluxo de energia, o ciclo de substâncias e o regime de espécies na paisagem (FORMAN; GODRON, 1986; LANG; BLASCHKE, 2009). Uma matriz formada por áreas construídas, que detém a dinâmica dos fluxos de matéria, energia e espécies na paisagem, estando imersa em uma extensa floresta urbana (44\% da paisagem), pode compor um cenário urbano muito mais equilibrado, principalmente do ponto de vista ecológico, devido todos os benefícios agregados à presença de vegetação em áreas urbanas e que influem diretamente na melhoria da qualidade do ar, da água e do solo.

Os fragmentos, classificados como as áreas com cobertura de vegetação presentes nas áreas verdes e no interior das áreas de quadra, totalizaram $164.705 .040 \mathrm{~m}^{2}$, ou 37,90\% da área total de Curitiba. Dentre os tipos de fragmentos, a maior área de cobertura $(91,49 \%)$ são de fragmentos introduzidos particulares e apenas 6,02\% são áreas de fragmentos remanescentes. Os fragmentos de perturbação e os introduzidos públicos representaram juntos, menos de $2,5 \%$ dos tipos de fragmentos (Figuras 1 e 2 ).

Os fragmentos introduzidos particulares corresponderam a mais de $90 \%$ da área de cobertura dentre os tipos de fragmentos, o que é preocupante. Alguns trabalhos reconhecem a importância dos jardins na paisagem urbana (REYES-PAECKE; MEZA, 2011; CAMERON et al., 2012). Entretanto, Cameron et al. (2012) advertem que o manejo de jardins particulares pode trazer mais danos do que benefícios ao ambiente, uma vez que não se tem estudos que avaliem o uso da água, de pesticidas ou fertilizantes nestas áreas. Se este alerta for levado em consideração, em conjunto com o fato destes jardins estarem em áreas particulares sujeitas a certa regulamentação de taxa de permeabilidade do solo, estas áreas podem ser consideradas vulneráveis.

Somente $6 \%$ da área de cobertura dos fragmentos foram classificados como fragmentos remanescentes. Em Curitiba este tipo de fragmento é pertencente às categorias parques e bosques do Sistema de Unidade de Conservação Municipal, formados pelas mais expressivas áreas de vegetação nativa remanescente da cidade. Heckmann, Manlez e Schlesinger (2008) afirmam que remanescentes de florestas contribuem significativamente para manter espécies nativas em áreas urbanas. O parque Barigui, por exemplo, foi apontado por Kozera, Dittrich e Silva (2006) como um fragmento remanescente de Floresta Ombrófila Mista 
com grande riqueza de espécies vegetais vasculares, mesmo estando situado em área urbana e sob interferência antrópica. São também refugio para mastofauna de médio porte como as capivaras (Hydrochoerus hydrochaeris), animais presentes em diversos parques da cidade (ALMEIDA et al., 2014).

Os fragmentos remanescentes ainda proporcionam ao ambiente urbano microclimas mais confortáveis termicamente, com menores temperaturas e maiores valores de umidade relativa do ar do que em áreas construídas e gramado (MARTINI; BIONDI, 2015) ou até mesmo em áreas verdes com paisagismo e arborização de ruas (MARTINI et al., 2015). Portanto, somente $6 \%$ dos fragmentos sendo classificados como remanescentes é muito pouco, principalmente em se tratando dos fragmentos de maior importância na paisagem.

Os corredores, definidos como a vegetação presente sobre o arruamento e os corpos d'água, representaram $24.916 .876 \mathrm{~m}^{2}$ ou $5,73 \%$ da área total da cidade. A maior área de cobertura dos corredores, $43,49 \%$, foram considerados urban stepping stones, ou seja, aqueles que possuem área igual ou menor que $500 \mathrm{~m}^{2}$, seguido por $30,74 \%$ de corredores de quadra, aqueles com área de 500 a $7.500 \mathrm{~m}^{2}$. Os corredores do tipo corpo d'água totalizaram 13,31\%, $7,09 \%$ foram classificados como corredores lineares e 5,37\% como corredores em faixa (Figuras 1 e 2).

A arborização viária já é reconhecida como corredor ecológico, sendo fundamental na estruturação do espaço urbano. Algumas pesquisas confirmam a eficácia dos corredores em áreas urbanas na melhoria da biodiversidade destas áreas (VERGNES; VIOL; CLERGEAU, 2012).

Curitiba possui $21 \%$ de sua área formada por sistema viário e corpos d'água, portanto, aproximadamente um quarto é coberto por corredores de vegetação. Considerar toda a vegetação sobre o arruamento como corredor, principalmente os corredores urban stepping stones, é avançar no conceito de conectividade e, consequentemente, no entendimento da floresta urbana. Entretanto, Bobrowski e Biondi (2012) constataram que a arborização viária de Curitiba encontra-se na fase madura ou de amadurecimento, ou seja, a longo prazo, se não houver um planejamento de reposição e um manejo adequado, a tendência é que haja uma diminuição destes corredores na cidade devido ao envelhecimento e perda das árvores. Os autores alertaram para a urgente necessidade de um plano de manejo adequado, contendo práticas modernas e sustentáveis para a conservação e compatibilização das árvores com as mudanças estruturais da cidade.

\section{Análise por regional da estrutura da paisagem da floresta urbana de Curitiba-PR}


Quando feita a análise da paisagem de cada regional, a definição da matriz teve de seguir dois critérios: primeiro a classe de maior cobertura do solo e, posteriormente, a classe de maior conectividade e controle da dinâmica da paisagem. A matriz de todas as regionais foi a área sem cobertura de vegetação, entretanto, para as regionais Bairro Novo e Santa Felicidade, a matriz foi definida utilizando-se o segundo critério, o da conectividade e controle da dinâmica da paisagem. Nestas regionais, a cobertura de vegetação nos fragmentos representa mais da metade de sua área. Entretanto, a área sem cobertura de vegetação possui maior conectividade, detém o controle da dinâmica da paisagem e é interligada e perfurada pela presença dos fragmentos e corredores de vegetação (Figura 3).

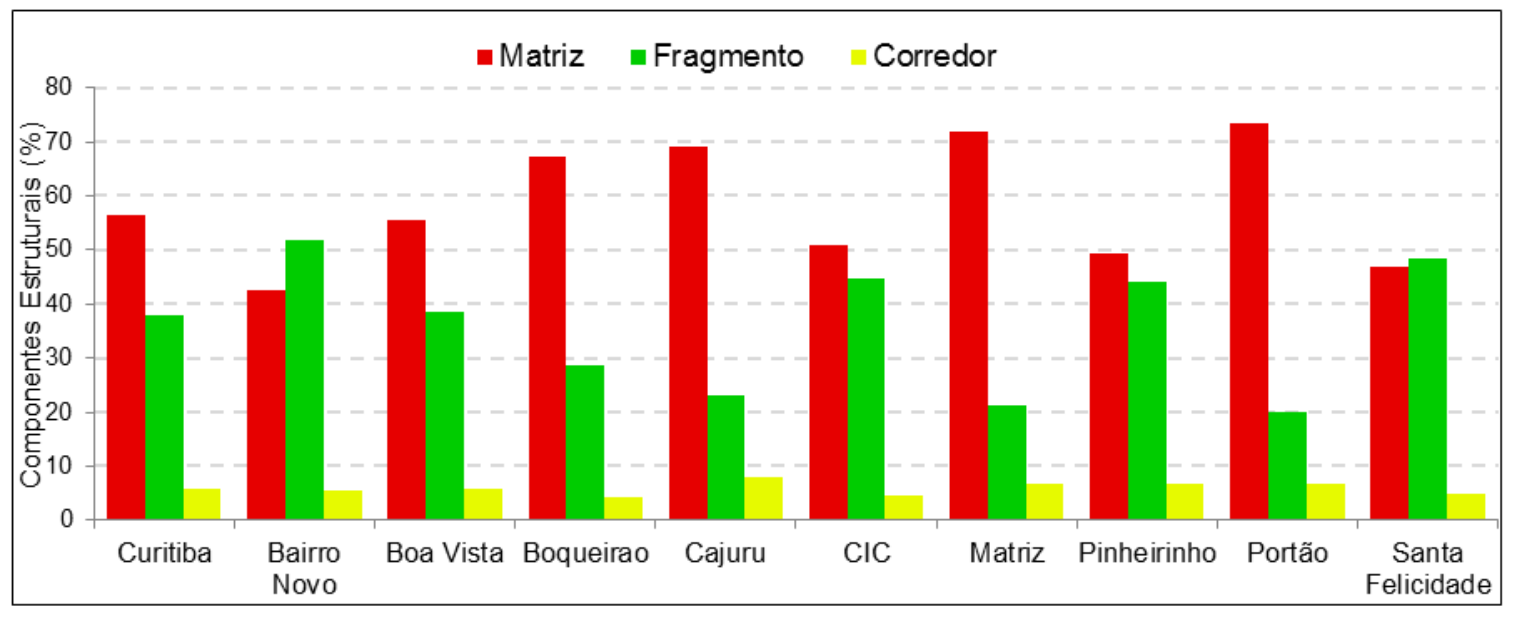

Figura 3. Componentes estruturais da paisagem da cidade de Curitiba-PR e de suas regionais Figure 3. Landscape structural components of Curitiba-PR and its regional

As regionais que apresentaram menor proporção de fragmentos por área foram Cajuru, Matriz e Portão, entretanto, estas foram as regionais que apresentaram a maior proporção de corredores. A regional Cajuru apresentou $7,87 \%$ de sua área formada por corredores, seguida pelas regionais Portão (6,78\%) e Matriz (6,73\%) (Figura 4). Este resultado é relevante, uma vez que justamente as regionais com a menor quantidade de fragmentos (cobertura de vegetação em áreas verdes e áreas particulares) apresentaram uma maior quantidade de corredores conectando estes fragmentos. Como esses fragmentos são em menor quantidade e encontram-se mais afastados os corredores acabam exercendo um papel ainda mais importante nestas regionais. 


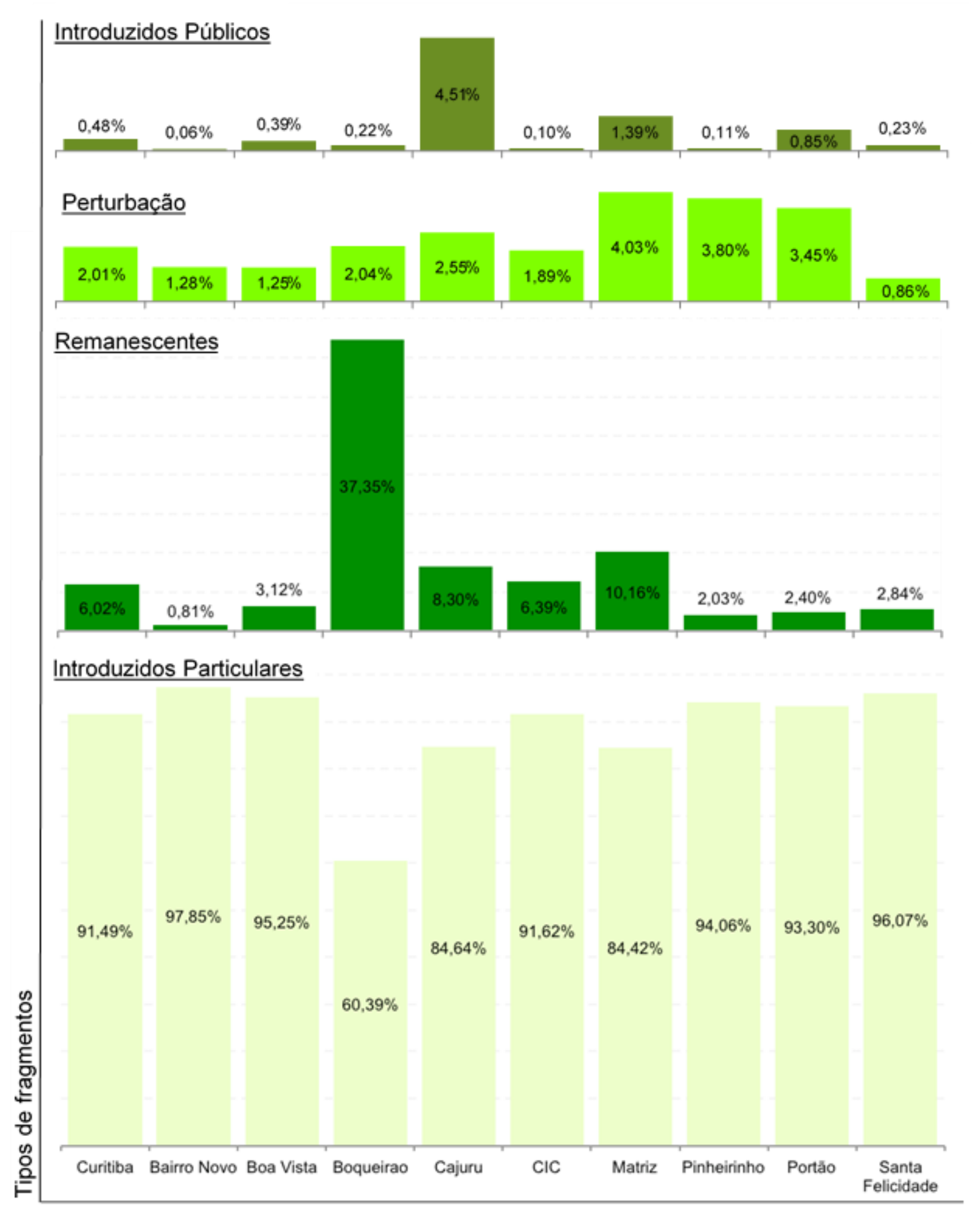

Figura 4. Tipos de fragmentos da cidade de Curitiba-PR e de suas regionais Figure 4. Patches types of Curitiba-PR and its regional 
Dentre os tipos de fragmentos, os fragmentos introduzidos particulares representaram maioria para todas as regionais, sendo que em seis regionais, estes superaram $90 \%$ da área de cobertura de vegetação dos fragmentos. Apenas as regionais Cajuru, Matriz e Boqueirão apresentaram valores inferiores. Agregado a isto, as regionais Cajuru e Matriz apresentam a segunda e a terceira maiores densidades populacionais de Curitiba, respectivamente. Segundo Michey, Schmitt-Harsh e Thurau (2013), em uma escala pequena ou "fina", a copa das árvores em áreas particulares de zonas residenciais com alta densidade populacional, se comportam de forma mais parecida com zonas comerciais, do que com zonas residenciais de baixa densidade, o que pode ser observado na regional Cajuru. Esta possui uma quantidade de fragmentos introduzidos particulares similar à regional Matriz, a qual contém a zona central (predominantemente comercial) da cidade. Em suma, devido a estas condições, a regional Cajuru se assemelha à regional Matriz.

A regional Boqueirão apresentou 60,39\% de fragmentos introduzidos particulares, e a maior proporção dentre as regionais de fragmentos remanescentes, 37,35\%. Este resultado revela a presença nesta regional do maior parque da cidade, o Parque Iguaçu. A regional Cajuru também é contemplada por parte da área do Parque Iguaçu, sendo a terceira regional em proporção de fragmentos remanescentes com 8,3\%. A regional Matriz apresentou 10,16\% de seus fragmentos como remanescentes, fato interessante por se tratar da região central da cidade. Isto é explicado pela grande quantidade de áreas verdes instituídas nesta regional dentre as quais, $14 \%$ do número total de parques e bosques de Curitiba, incluindo o Parque Barigui, o segundo maior parque da cidade em área (Figura 4).

A regional Matriz também se destacou quanto à presença de fragmentos de perturbação, como as praças e eixos de animação, os quais representaram $4 \%$ de seus fragmentos. Esta é a regional com maior área coberta por vegetação em praças e eixos de animação, que se deve ao fato desta regional possuir $20 \%$ do número destas categorias de áreas verdes em Curitiba (Figura 4). Os resultados corroboram com Biondi e Lima Neto (2012), segundo os quais a regional Matriz contém o maior número de praças de Curitiba, que não deve estar associado com a maior cobertura de vegetação total da regional. Isso também pode ser observado nesta pesquisa, já que esta regional possui a segunda menor área coberta por vegetação da cidade.

Em contra ponto, a regional Santa Felicidade, que possui a segunda maior floresta urbana da cidade, apresentou a menor proporção de fragmentos de perturbação $(0,86 \%)$. Santa Felicidade é a regional com o menor número de praças e eixos de animação, apenas 44 (Figura 4). Isto pode estar associado ao fato desta ser a regional com menor densidade demográfica de Curitiba, 23,90 hab/ha, fato também observado por Biondi e Lima Neto (2012). 
Os fragmentos introduzidos públicos, aqueles representados pelos jardinetes, largos, jardins ambientais, núcleos ambientais e centro poliesportivo, foram o tipo de fragmento de menor representatividade dentre os tipos de fragmentos, com menos de $2 \%$ em todas as regionais, exceto nas regionais Cajuru e Matriz, com 4,51 e 1,39\%, respectivamente. A regional Cajuru se sobressai às demais regionais neste tipo de fragmento por possuir o único centro poliesportivo da cidade, representando $4,77 \%$ da área total de áreas verdes desta regional. Já a regional Matriz detém o maior número destas categorias de áreas verdes, $27 \%$ do total da cidade (Figura 4).

Em relação aos tipos de corredores, a maioria das regionais possui predominância de urban stepping stones, aqueles com área inferior a $500 \mathrm{~m}^{2}$. O maior valor de corredores urban stepping stones foi encontrado para a regional Boqueirão (68,05\%) e o menor para a regional Pinheirinho (21,39\%). Os corredores em faixa foram os de menor representatividade para a maioria das regionais e não tiveram ocorrência nas regionais Matriz e Portão (Figura 5).

Dentre as regionais, a Matriz foi a que apresentou a maior proporção de corredores em quadra $(44,02 \%)$ e a menor proporção de corredores em corpos d'água, não tendo apresentado corredores em faixa. Este resultado é interessante, uma vez que esta é a regional central da cidade e apresentou a maior parte de seus corredores como corredores em quadra, ou seja, aqueles que apresentam área padrão de arruamento presente ao longo de uma quadra (de 500 a 7.500 m2) (Figura 5). Em estudo realizado por Martini, Biondi e Batista (2013), os autores compararam variáveis microclimáticas em ruas arborizadas e sem arborização em três bairros de Curitiba, sendo dois localizados na regional Matriz. Os autores constataram que a temperatura do ar nas ruas arborizadas estiveram abaixo dos valores das ruas sem arborização, enquanto o inverso ocorreu para a umidade relativa. Desta forma, os autores concluíram que arborização de ruas proporciona um microclima urbano mais ameno durante a maior parte do dia. Portanto, possuir a maioria dos corredores de vegetação em quadra proporciona à regional Matriz uma melhoria da qualidade ambiental da porção da cidade de maior circulação de pessoas, a região central. 


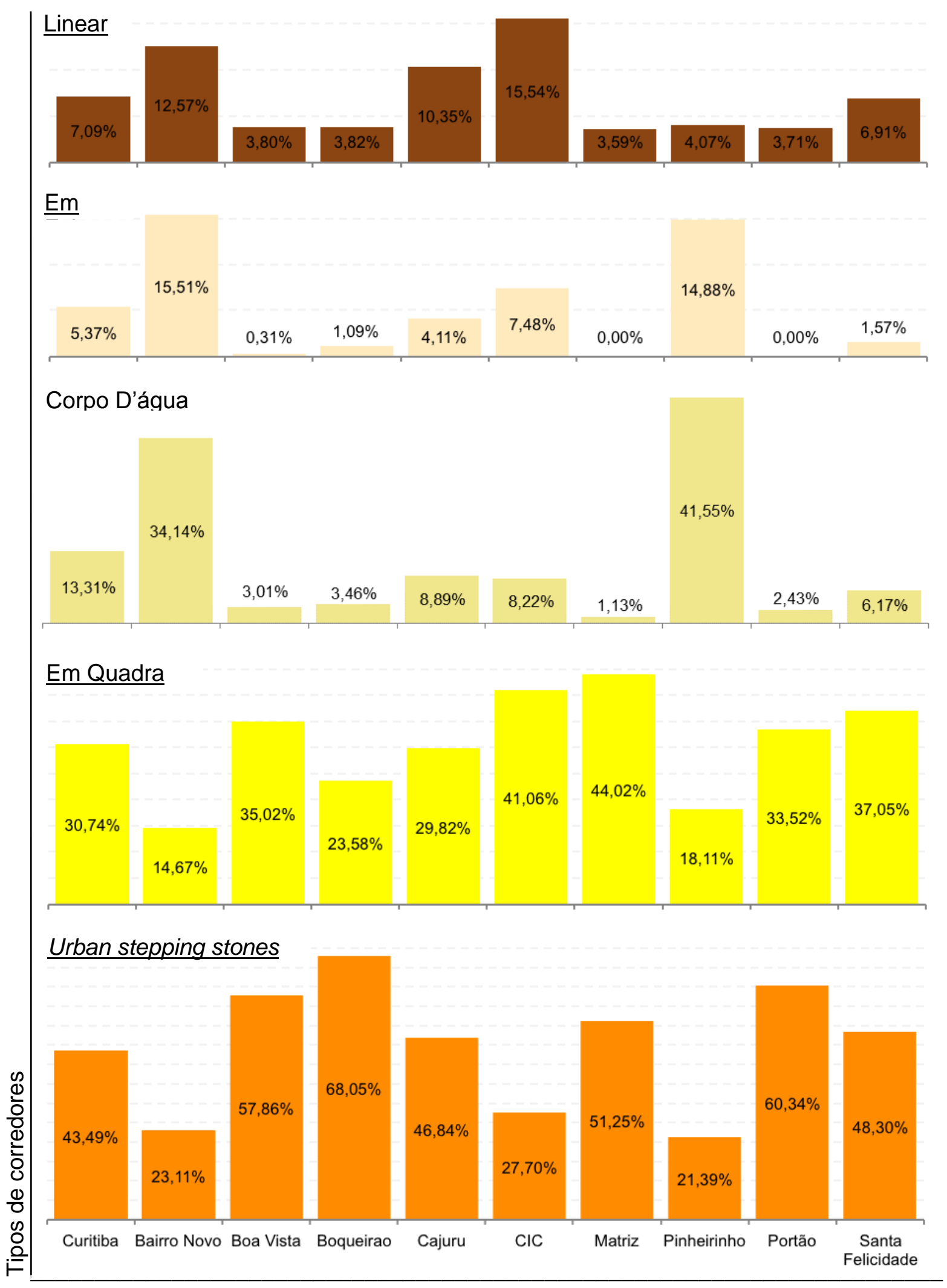

Regionais

Figura 5. Tipos de corredores da cidade de Curitiba-PR e de suas regionais

Figure 5. Corridors types of Curitiba-PR and its regional 
Costa (2010) utilizou-se de imagens de satélite de alta resolução espacial para identificar locais prioritários para a instalação de corredores verdes na cidade de São PauloSP. A autora, entretanto, definiu os corredores como faixas contínuas e lineares de vegetação. Isto se justificou uma vez que o objetivo principal era instalar tais corredores em áreas de declividade e alagamento e assim mitigar tais problemas. Para esta pesquisa, procurou-se identificar toda a cobertura de vegetação de Curitiba e relacioná-la aos padrões espaciais do estudo da paisagem. Portanto, a abordagem de inclusão dos corredores urban stepping stones como integrantes da arborização viária, ainda que não fisicamente conectadas, se mostrou pertinente.

Alguns estudos atestam a efetividade de corredores em áreas urbanas, principalmente em organismos de baixa capacidade de dispersão e aves (VERGNES; VIOL; CLERGEAU, 2012; VERGNES; KERBIRIOU; CLERGEAU, 2013), os quais tendem a ser os maiores beneficiados pelos corredores urban stepping stones.

Considerando a riqueza da avifauna curitibana, 367 espécies registradas (STRAUBE et al., 2009), esse conceito inovador de corredor tende a ganhar maior importância. Para Straube et al. (2009) pequenas ilhas de vegetação florestada ou apenas arborizada, nativa ou não, são importantes pontos de passagem para a avifauna entre os remanescentes isolados. Os autores inclusive as intitulam como stepping stones.

\section{CONCLUSÕES}

A paisagem de Curitiba é formada por uma matriz urbana, a qual ocupa 56,33\% da área total do município. Os fragmentos, classificados como as áreas com cobertura de vegetação presentes nas áreas verdes e no interior das áreas de quadra, ocupam 37,90\% da cidade. Os corredores, definidos como a vegetação presente sobre o arruamento e os corpos d'água, representam $5,73 \%$ da área total da cidade.

Dentre os tipos de fragmentos de vegetação, os caracterizados como introduzidos particulares são a grande maioria (91,49\%). Existe uma deficiência de fragmentos remanescentes, os quais representam apenas $6 \%$ dos tipos de fragmentos.

Os corredores de vegetação cobriram cerca de um quarto da área de arruamento e corpos d'água da cidade, sendo a maioria (43,49\%) os urban stepping stones.

A nova abordagem dada aos corredores denominados de urban stepping stones foi coerente com sua quantidade e função estratégica na paisagem já que as regionais com a menor quantidade de fragmentos apresentaram uma maior quantidade de corredores conectando estes fragmentos, que em menor quantidade encontram-se mais afastados. 
Ainda que Curitiba detenha uma matriz formada por áreas construídas, imersa em uma extensa (44\% da paisagem) floresta urbana, há necessidade de um incremento no número de fragmentos remanescentes, de uma efetiva fiscalização que evite a perda dos fragmentos introduzidos particulares e um monitoramento e manejo adequado dos corredores urban stepping stones.

\section{REFERÊNCIAS}

ALMEIDA, A. M. R.; GRISE M. M.; BIONDI, D.; SILVA FILHO, D. F. Estudo de habitat urbano de mamífero nativo Hydrochoerus hydrochaeris (capivara) com uso de Sensoriamento Remoto, Curitiba, Paraná, Brasil. Ciência e Natura, Santa Maria, RS, v. 36, p. 277-286, 2014.

BIONDI, D. Floresta Urbana: Conceitos e Terminologias. In: BIONDI, D. Floresta urbana. Curitiba, 2015.

BIONDI, D.; LIMA NETO, EM. Distribuição espacial e toponímia das praças de Curitiba-PR. Revista da Sociedade Brasileira de Arborização Urbana, Piracicaba, SP, v. 7, n. 3, p. 31-43, 2012.

BOBROWSKI, R.; BIONDI, D. Distribuição e dinâmica da área de copa na arborização de ruas de Curitiba, Paraná, Brasil, no período de 1984-2010. Revista Árvore, Viçosa, MG, v. 36, n. 4, p. 625-635, 2012.

CAMERON, R. W. F.; BLANUSA, T.; TAYLOR, J. E.; SALISBURY, A.; HALSTEAD, A. J.; HENRICOT, B.; THOMPSON, K. The domestic Garden: its contribution to urban green infrastructure. Urban Forestry \& Urban Greening, Amsterdam, Holanda, v. 11, p. 129-137, 2012.

COSTA, J. A.; SILVA FILHO, D. F.; POLIZEL, J. L. Uso de imagens de alta resolução para avaliação de áreas verdes na cidade de São Paulo, Brasil. Revista da Sociedade Brasileira de Arborização Urbana, Piracicaba, SP, v. 7, p. 158-180, 2012.

CURITIBA. Decreto n. 427, de1983. Define critérios para denominação de áreas públicas ajardinadas. Diário Oficial do Município, Curitiba, PR, 1983.

CURITIBA. Lei n. 2.942 de 27 de dezembro de 1966. Define Normas para aprovação de arruamentos, loteamentos e desmembramentos de terrenos no município de Curitiba. Diário Oficial do Município, Curitiba, PR, 1966.

FORMAN, R. T. T.; GODRON, M. Landscape ecology. USA: J. Wiley, 1986.

HECKMANN, K. E.; MANLEY, P. N.; SCHLESINGER, M. D. Ecological integrity of remnant montane forests along an urban gradient in the Sierra Nevada. Forest Ecology and Management, Amsterdam, Holanda, n. 255, p. 2453-2466, 2008.

INSTITUTO DE PESQUISA E PLANEJAMENTO URBANO DE CURITIBA (IPPUC). Curitiba em dados. Curitiba, 2014. Disponível em: <http://curitibaemdados.ippuc.org.br/>. Acesso em: ago. 2014. 
KOZERA, C.; DITTRICH, V. A. de O.; SILVA, S. M. Composição florística da floresta ombrófila mista montana do parque municipal do Barigui, Curitiba, PR. Revista Floresta, Curitiba, PR, v. 36, n. 1, jan./abr. 2006.

LANG, S.; BLASCHKE, T. Análise da Paisagem com SIG. São Paulo: Oficina dos Textos, 2009.

MARTINI, A.; BIONDI, D.; BATISTA, A. C. Variação diária e estacional do microclima urbano em ruas arborizadas de Curitiba-PR. FLORAM - Revista Floresta e Ambiente, Rio de Janeiro, RJ, v. 20, n. 4, p. 460-469, 2013.

MARTINI, A.; BIONDI, D. Microclima e conforto térmico de um fragmento de floresta urbana em Curitiba, PR. FLORAM - Revista Floresta e Ambiente, Rio de Janeiro, RJ, v. 22, p. 182-193, 2015.

MARTINI, A.; BIONDI, D. ; BATISTA, A. C.; SILVA FILHO, D. F. Microclima em diferentes tipologias de floresta urbana. Revista da Sociedade Brasileira de Arborização Urbana, Piracicaba, SP, v. 10, p. 12-22, 2015.

MICHEY, S. K.; SCHMITT-HARSH, M.; THURAU, R. Zoning, land use, and urban tree canopy cover: the importance of scale. Urban Forestry \& Urban Greening, Amsterdam, Holanda, v. 12, p. 191-199, 2013.

REYES-PAECKE, S.; MEZA, L. Jardines residenciales en Santiago de Chile: extensión, distribución y cobertura vegetal. Revista Chilena de Historia Natural, Santiago, Chile, v. 84, p.581-592, 2011.

STRAUBE, F. C.; CARRANO, E.; SANTOS, R. E. F.; SCHERER-NETO, P.; RIBAS, C. F.; MEIJER, A. A. R.; VALLEJOS, M. A. V.; LANZER, M.; KLEMANN JUNIOR, L.; AURÉLIOSILVA, M.; URBEN FILHO, A.; ARZUA, M.; LIMA, A. M. X. de; SOBÂNIA, R. L. M.; DECONTO, L. R.; BISPO, A. A.; JESUS, S. de; ABILHÔA, V. Aves de Curitiba: coletânea de registros. Curitiba: PMC, 2009.

VERGNES, A.; KERBIRIOU, C.; CLERGEAU, P. Ecological corridors also operate in an urban matrix: a test case with garden shrews. Urban Ecosyst, Nova York, USA, v. 16, p. 511-525, 2013.

VERGNES, A.; VIOL, I Le.; CLERGEAU, P. Green corridors in urban landscapes affect the arthropod communities of domestic gardens. Biological Conservation, Grã-Bretanha, Reino Unido, v. 145, p. 171-178, 2012.

VIEIRA, C. H. S. D.; BIONDI, D. Análise da dinâmica da cobertura vegetal de Curitiba, PR (de 1986 a 2004), utilizando imagens Landsat TM. Revista Árvore (Impresso), Viçosa, MG, v. 32, p. 479-487, 2008.

WOODALL, C. W.; NOWAK, D. J.; LIKNES, G. C.; WESTFALL, J. A. Assessing the potential for urban trees to facilitate forest tree migration in the eastern United States. Forest Ecology and Management, Amsterdam, Holanda, v. 259, p. 1447-1454, 2010. 